\title{
Effects of Water Deck on Rock Blasting Performance
}

Hyongdoo Jang a1, David Handel ${ }^{b}$, Younghun Ko ${ }^{c}$, Hyung-Sik Yang ${ }^{c}$, and James Miedecke ${ }^{d}$

a Department of Mining Eng. and Metallurgy Eng., Western Australian School of Mines, Curtin University, Australia

${ }^{\mathrm{b}}$ Operations and Technical Director, Reynolds Soil Technologies Pty Ltd and BLASTBOSS Pty Ltd., Australia

${ }^{c}$ Department of Energy and Resources Engineering, Chonnam National University, South Korea

${ }^{d}$ Mining and Civil Engineering Specialist, Proof Engineers Pty Ltd Australia

\begin{abstract}
Water in the blasthole causes adverse effects on blasting performances, e.g., the incomplete explosion of explosive and toxic fume generation. It is normally pumped out before explosive loading to prevent explosive deterioration. In this study, a new blasting concept - water deck blasting (WDB) is introduced which sealed the water at the blasthole bottom to prevent adverse effects of water as well as maximise the beneficial effect of water on rock breakage performances. A field experiment was conducted in a quarry, bench blasting including 23 watery holes among 139 blastholes. Promising results were observed as there was no evidence of toxic fume during blasting and achieved a competent level of fragmentation with even toe-cut at the bottom level. The WDB and a normal charge blast were simulated using ANSYS/AUTODYN and multi-peak oscillations were investigated for the WDB. The advantageous rock breakage performances of the relatively small amount of water rather than the amount of explosive have not been verified but have been discussed referring to the extreme water and the steam explosion phenomenon. The WDB blasting method expects to bring advantageous effects to surface mine blasting.
\end{abstract}

Keywords: rock blasting; water deck blasting; blasting performance; steam explosion

\section{Introduction}

In typical rock blasting exercises in surface mines, often the dynamic or static water level at the bottom of the borehole is unavoidable, which is known for causing several adverse effects on the blasting performance. In fact, many researchers and engineers have pointed out the water and

\footnotetext{
${ }^{1}$ Corresponding author:

Locked bag 30, Kalgoorlie, WA, 6433, Australia, Tel.: +61 89088 6195; Fax: +61 890886151

E-mail address: hyongdoo.jang@curtin.edu.au (Hyongdoo Jang)
} 
humidity in a borehole as a primal causing factor for misfire, incomplete explosion, sympathetic detonation, dead pressure effect, and generation of toxic NOx fumes. The majority of adverse effects of the water in a borehole to blasting performances are due to the deterioration of the explosive. If water can be perfectly sealed, then the beneficial influence of the water on rock blasting performance would be maximised. In this study, water deck blasting (WDB) is presented, which could maximise the benefits of water in borehole but minimise the negative influences of water on the explosion performance.

In the following Chapter 2, the different aspects of water effects on rock blasting performance are discussed. Subsequently, in Chapter 3, the effects of water deck blasting (WDB) have been examined through numerical analysis. In succession, a field trial of water deck blasting (WDB) is presented in Chapter 4. Chapter 5 discusses fewer unique phenomena observed in this study. Also, a logical deduction has been made on the advantageous effects of the water deck by discussing the 'extreme water' and 'steam explosion'. The study is concluded in Section 6 with presenting conclusions and future studies.

\section{Water effects on blasting performance}

Ineffective blasting performances due to the watery borehole negatively influence the productivity of mines by causing poor fragmentation, poor level cut, back-break, and blasthole blowup. They also increase the environmental and safety risks resulting in the excessive vibration, fly rock, and toxic fumes. The majority adverse effects of the watery boreholes are caused by the incomplete explosion of the water contaminated explosives. In other words, the rate of adverse effects will be minimised if the water is completely isolated from the explosive column, which facilitates a complete explosion. The complete explosion would maximise rock breakage performances and minimise the adverse effects of watery borehole, by creating significant synergies with the favourable rock breaking conditions of the saturated rock mass, increasing the duration time of the induced explosion energy actions inside of the rock mass, and stress oscillation due to the water in a borehole.

\subsection{Adverse effects of water in borehole}

The majority of adverse effects of the water on blasting performances are due to the deterioration of the explosive. When explosives are immersed 24 hours in water, ANFO will loss $98 \%$ of Ammonium nitrate (AN) while the water-in-oil based emulsion explosives loss $0.5 \% \mathrm{AN}^{1}$. The degree of adverse influences of the water would be varied in different types of explosives but it is unavoidable when the water present in the borehole and directly in contact with explosives. 
The degree of explosive deterioration due to water depends on the period of explosive sleeping time in a borehole and the wetness of the borehole. The phenomenon can cause serious of changes on chemical components of adjacent explosive. Especially hygroscopic explosives, e.g., ammonium nitrate fuel oil (ANFO), the moistened explosive becomes desensitised and often failed to detonate. Given that the adverse effects, the water in a borehole would result shorten the diameter of the detonable explosive column, decelerate the velocity of detonation (VOD), toxic fume due to the incomplete explosion, and residual explosive in a borehole in a severe condition. Due to the watery borehole wall and the deteriorated explosive along the borehole wall, the VOD at wet borehole would be significantly slower than the VOD at the dry borehole.

\subsection{Beneficial effects of water in borehole}

The presence of water in a borehole could be beneficial for rock breakage performance if the water is thoroughly sealed. The beneficial effects of water in a borehole on the blasting performance have been hardly studied. Few studies on water-coupled and water-cushion blasting had been conducted in China for the blasting performance improvement and blasting induced vibration control ${ }^{2-6}$.

\subsubsection{Effects of rock saturation to blasting damage zone}

In general, the stress wave velocity is faster in the saturated rock than the dry rock. In addition, the strength of rock will be decreased when it is saturated $\left(S_{d r y} \gg S_{s a t}\right)$. Kim, Changani ${ }^{7}$ conducted a research to find the effects of water contents on the mechanical strength of rock. The research found that both compressive and tensile strength of saturated rock samples were reduced approximately $20 \%$ compared with dry samples in both static and dynamic loading conditions. Figure 1 demonstrates three different scenarios of surface blasting: (a) normal charge in a dry ground, (b) normal charge in a saturated ground at the bottom of borehole wall, and (c) sealed charge in a saturated ground condition as (b). 

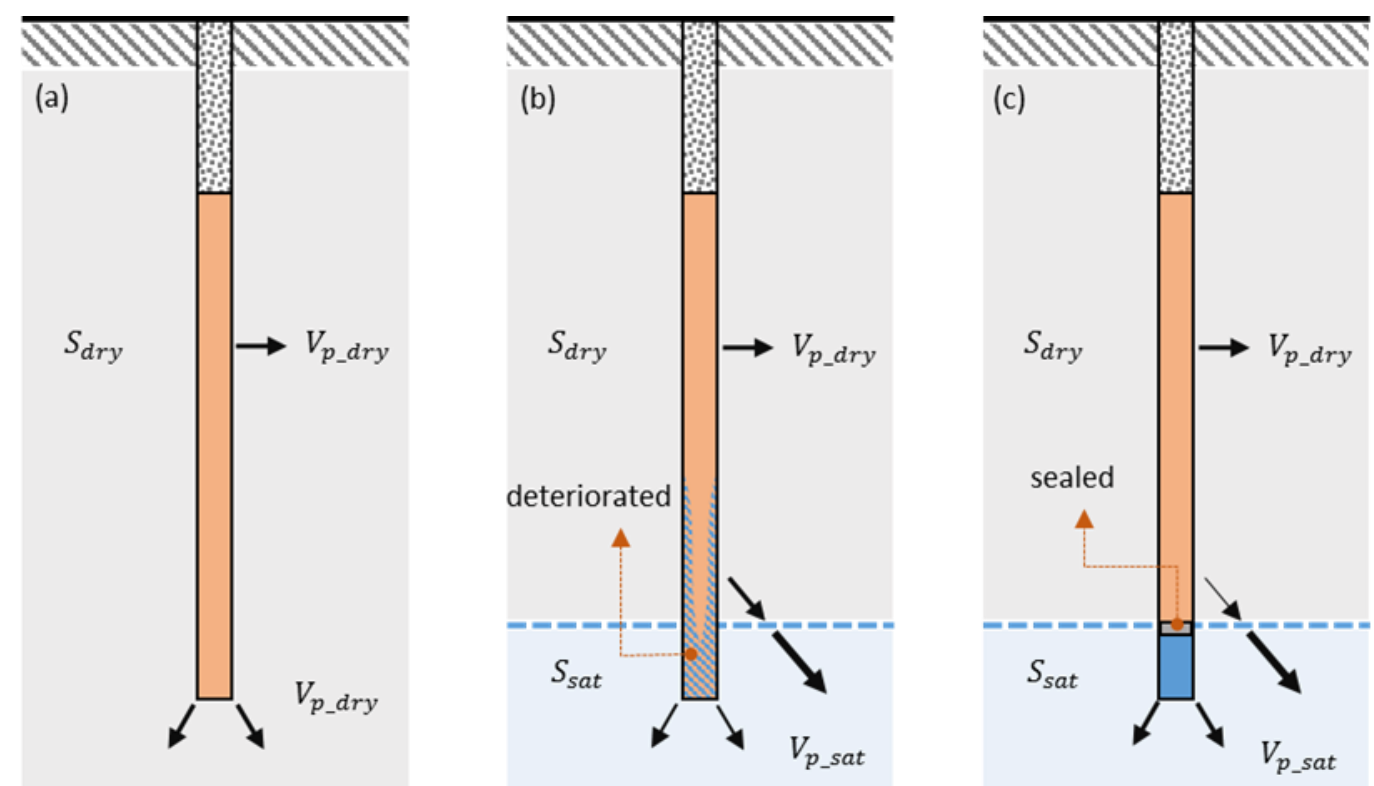

Figure 1. Rock strength and stress wave velocity comparison of dry and wet boreholes. (a) Dry borehole, (b) Wet borehole due to the water table at the bottom of borehole, and (c) Wet borehole sealing the water at the bottom of borehole.

Cui, Yuan, Yan ${ }^{5}$ conducted a research on water-silt composite blasting to substitute the conventional silt stemming blast for tunnelling. The research observed huge wave reflections in the water and the performance of water bubbles and vapour during the rock breaking processes. Moreover, the research illustrates the performances of wet and dry silt charges through the blasting damage zone (BDZ) calculation by applying Eq. 1.

$$
R_{p}=\left(\frac{(\mu /(1-\mu)) P_{r}}{\sigma_{t}}\right)^{1 / \alpha} r_{b}
$$

Where $R_{p}$ is the radius of $\mathrm{BDZ}, \mu$ presents Poisson's ratio, $\sigma_{t}$ is the tensile strength of rock, $\alpha$ is attenuation parameter, $P_{r}$ is the borehole pressure, $r_{b}$ presents the radius of blast hole.

In general, the Poisson's ratio $(\mu)$ tends to be increased along with decreasing Young's Modulus $(E)$ when rock becomes saturated. Thus, from the Eq. $1, R_{p}$ becomes larger in a saturated rock than a dry rock if explosive charge conditions and attenuation parameters are identical. Figure 2 shows the relation between Poisson's ratio and the BDZ when $\alpha$ is 0.50 . It can be seen that when Poisson's ratio increases from 0.25 (Dry rock) to 0.35 due to saturation, the radius of Blasting Damage Zone (BDZ) is increased to 2.6 times of BDZ of Dry rock. 


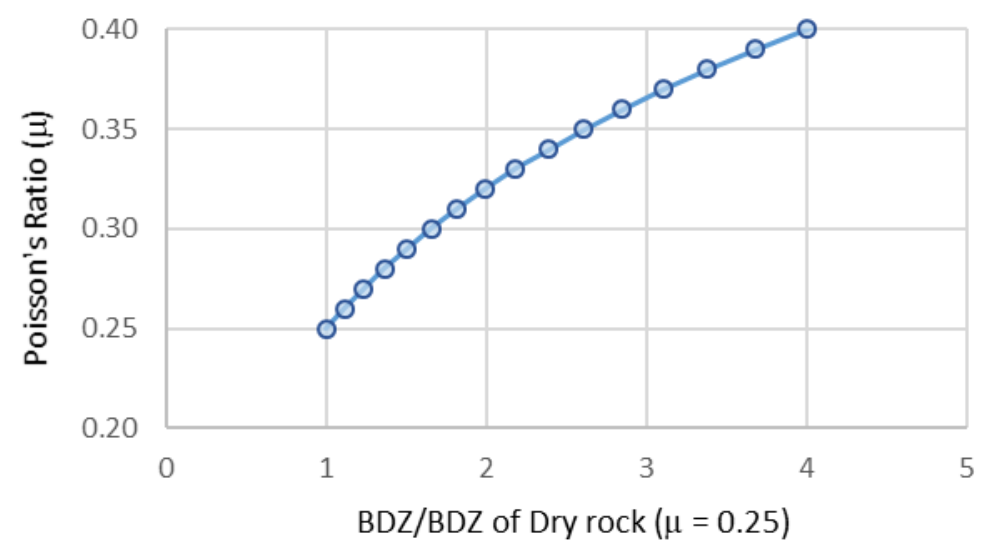

Figure 2. The relation between Poisson's Ratio and Blasting Damage Zone (BDZ)

\subsubsection{Blasting pressure oscillation}

In case of underwater explosion, the continuous oscillation of the impulsively expended gas bubble creates a pulse crossing negative and positive pressures due to the inertia of the water and the elastic properties of the gas bubble ${ }^{8}$. The continuous dynamic pressure transforms due to the underwater explosion causes saviour damage on the adjacent structure than the same magnitude of an explosion in the air. Similar phenomena have been observed in rock damage under cyclic loading. Rock strength deterioration under cyclic loading has been recognised by Many researchers ${ }^{9-11}$. The rate of strength deterioration is a function of the loading amplitude and the maximum loading on each cycle and the rock strength under cyclic loading can be reduced around $30 \%$ of strength in monotonic loading with increasing micro cracks in the rock. Recently, Zhou et al. ${ }^{12}$ researched to examine the effects of cyclic pumping to rock during the hydraulic fracturing operation. Through the study, more complex microcracks have been observed when cyclic loading is loaded with variable frequency rather than regular frequency pumping and monotonic loading.

The detonation behaviour of water deck blasting (WDB) cannot be fully elucidated with the underwater explosion or the rock strength deterioration under cyclic loading. However, a pressure transform in the form of cyclic loading has been observed at the bottom of a blast hole through a numerical simulation using AUTODYN ${ }^{13}$. Given the strength deterioration due to cyclic loading and pressure transform, the observed cyclic loading at the borehole bottom of the WDB contributes to exacerbating the rock fracturing process.

\subsubsection{Energy encapsulation}

Once the explosive is detonated inside of a blasthole, extreme amounts of explosion energy will be instantaneously discharged. The induced shock waves penetrate rock masses and promote microcracks within $1-2$ ms after the detonation. The cracks will be expanded and rock fragments will be pushed away by the blast-induced high-pressure gases. Not all the energy from the rapid 
chemical reaction of explosive would contribute to rock breakage. According to previous studies, around $7-25 \%$ of explosion energy would be effectively spent for rock breakage in forms of fracture, seismic, and kinetic energies, while $30 \%$ of energy would be lost through gas venting to atmosphere. The uncounted remaining $40-60 \%$ of explosion energy would be transferred from gases to rock fragments to heat and deform the rock fragments ${ }^{14,15}$. Given the high rate of energy loss during the rock blasting, the breakage performance would be improved by increasing the duration time of the induced explosion energy actions inside of the rock mass. The blast incident energy would be encapsulated with layers of different materials. Needham ${ }^{16}$ conducted air explosion experiments to investigate the burst effects of a snow layer on a concrete surface. A $453.59 \mathrm{~kg}$ (1000 pound) of explosive composing with $85 \%$ of $\mathrm{HMX}$ was detonated at $150 \mathrm{~cm}$ above the concrete surface with and without a snow layer. Through the experiment, it was found that the snow layer is not functioned as a cushion of the impact but encapsulates the blast incident energy. The result shows that the overpressure in the snow layer was nearly three times higher than the one on the exposed concrete surface. Due to the impedance differences between air and the snow layer, the sound speed in the snow layer has been reduced which blocked the rapid transmission of the blast incident energy in the snow layer. In case of water deck blasting (WDB), the water deck located at the bottom of the blast hole can be accounted as an energy encapsulation layer which extends the action moment of blast incident energy to the adjacent rock masses.

\section{Comparison numerical study of conventional and water deck blasting}

\subsection{Rock blasting processes}

The explosion is a rapid reaction of fuel and oxidiser in explosive which generates exceptionally high pressure and gases. The reaction ignites detonation waves, which travels at supersonic speeds of around 2000 to $7000 \mathrm{~m} / \mathrm{s}$. At the same time, the shock wave will penetrate through the rock mass. The adjacent rock to the explosion will reach a hydrodynamic state and pulverised as it exhibits an inelastic response. A nonlinear zone will come after the hydrodynamic zone, where the rock will be experienced from plastic deformations to severe fracturing. Beyond the nonlinear zone, rock will be in an elastic zone. In the elastic zone, compressive failure does not occur as the amplitude of blasting induced compressive pressure will become either same or lower than the compressive strength of the rock. However radial fractures will be generated as the tangential stress is still higher than the tensile strength of the rock. 


\subsection{Blast modelling using AUTODYN/ANSYS}

Numerical analysis is carried out using AUTODYN from ANSYS to examine the effect of water deck at the bottom of the borehole. AUTODYN is a non-linear hydrocode that enables to simulate non-linear dynamic impacts incorporating Lagrange, Euler, ALE (Arbitrary Lagrange Euler), and mesh free solver. The program has been widely used for blasting loading analysis ${ }^{17-21}$. In this study, the hybrid Lagrangian/Eulerian method is applied. The rock and sand are modelled with Lagrangian solvers, whereas explosives and air are modelled with Eulerian solvers, which is ideal for hydrodynamic behaviour modelling as it does not occur grid distortion. Jones-Wilkins-Lee (JWL) equation of state (EOS) is adopted as it can demonstrate the relations between expanding volume and pressure of an explosion. The JWL EOS describes thermodynamics of detonation product and unreacted high explosives using in reactive hydro simulations. One of the limitations of the JWL equation is that the parameters in JWL equation may unintentionally adjust to fit data to calibrate an explosion experiment, i.e., the cylinder expansion test, with the non-ideal behaviour of pressure and volume from explosion ${ }^{22}$. Nevertheless, The JWL EOS has been extensively used to model non-ideal detonations and the equation is presented in Eq. 2.

$$
P=A\left(1-\frac{\omega}{R_{1} V}\right) e^{-R_{1} V}+B\left(1-\frac{\omega}{R_{2} V}\right) e^{-R_{2} V}+\frac{\omega E_{0}}{V}
$$

Where $P$ is the pressure, $V$ is the relative volume of detonation pressure defined by the density of explosive $\left(\rho_{e}=0.931 \mathrm{~g} / \mathrm{cm}^{3}\right)$ over the density of the detonation products $\left(\rho_{p}\right), E_{0}$ presents the specific energy with an initial value of $E_{0}^{e}$. The material parameters for the explosive are as follows: $A, B, R_{1}, R_{2}, \omega$ and $E_{0}^{e}$ are $4.95 \mathrm{E}+10 \mathrm{~Pa}, 1.89 \mathrm{E}+9 \mathrm{~Pa}, 3.907,1.118,0.333$, and $2.67 \mathrm{E}+6 \mathrm{~J} / \mathrm{kg}$ respectively. The Chapman-Jouguet (CJ) detonation velocity and pressure are $4160 \mathrm{~m} / \mathrm{sec}$ and 5.15E+9 Pa respectively.

\subsection{Geometry of the blast model}

The blasting simulation aims to compare the blasting performances at the blasthole bottom in a case of a normal charge (a dry hole) and water deck charge. The bench blast model for this study incorporating one blasthole presents a dry hole condition where the blasthole diameter, depth, stemming length, and charge column length are $102 \mathrm{~mm}, 14.0 \mathrm{~m}, 2.8 \mathrm{~m}$, and $11.2 \mathrm{~m}$ respectively. Subsequently, $1.12 \mathrm{~m}$ of explosive column at the blasthole bottom is replaced with water column (10\% of explosive column length) to examine the effects of water deck, which is assumed as perfectly sealed from the explosive. Figure 3 demonstrates the schematic view of the blast simulation model with a water deck. 


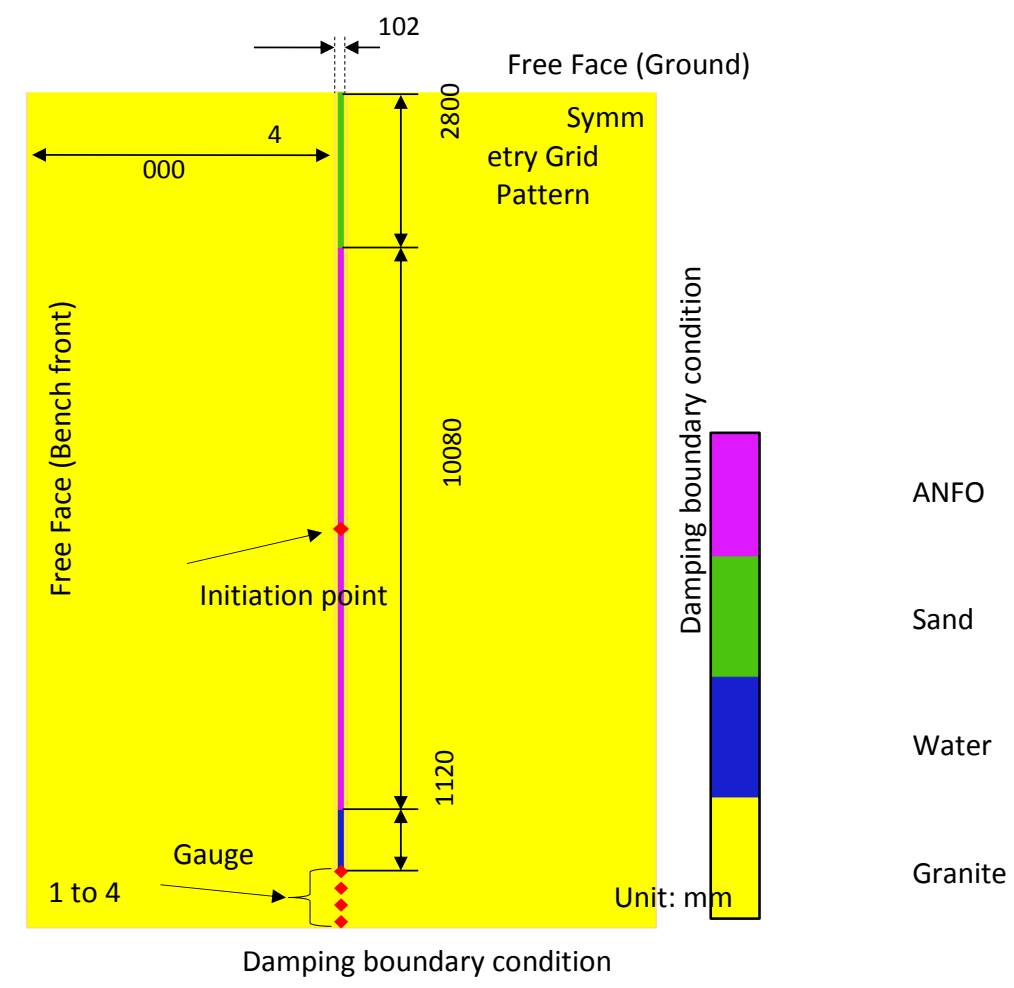

Figure 3. Schematic view of the 2D numerical model of water deck blasting

The model comprises 5 materials, i.e., air, ANFO, sand, water, and granite. The material constants were taken from ANSYS engineering data library ${ }^{23}$. Air $^{24}$ in the model has density and specific heat of $1.22 \mathrm{E}-03 \mathrm{~g} / \mathrm{cm}^{3}$ and $7.17 \mathrm{E}+02 \mathrm{~J} / \mathrm{kg} / \mathrm{K}$ respectively. Density and shear modulus of the sand ${ }^{25}$ are $2641 \mathrm{~kg} / \mathrm{m}^{3}$ and $7.69 \mathrm{E}+7$ Pa respectively, and it was applied in the model as a stemming material. The thermodynamic reactions of water ${ }^{26}$ was solved by Mie-Gruneisen EOS, and its parameters are taken from ANSYS material library of which density, material constants of $\mathrm{C} 1, \mathrm{~S} 1$, and Gruneisen coefficient are $998 \mathrm{~kg} / \mathrm{m}^{3}, 1647 \mathrm{~m} / \mathrm{s}, 1.912$, and 0 respectively. Parameters of the granite were obtained from ANSYS engineering data library. The property of granite, such as density, P-wave velocity, and shear modulus are $2.52 \mathrm{~g} / \mathrm{cm}^{3}, 3.24 \mathrm{E}+3 \mathrm{~m} / \mathrm{s}$, and $1.70 \mathrm{E}+4 \mathrm{MPa}$ respectively. Hermann's $\mathrm{P}$-alpha $\mathrm{EOS}^{27}$ and RHT damage mode ${ }^{28}$ were used in this study to simulate the dynamic nonlinear behaviour of rock-like materials in high strain rate under the blast loading. More details of the Palpha model and RHT damage model can be found in Herrmann ${ }^{27}$, Collins ${ }^{29}$, and Riedel ${ }^{30}$.

\subsection{ANTODYN simulation results}

The pressure-time histories at the blasthole bottom of normal blasting (Figure 4-a) and water deck blasting (Figure 4-b) are demonstrated in Figure 4. For the normal blasting (NB), the initial peak pressure at the blasthole bottom was reached $2700 \mathrm{MPa}$ at $1.47 \mathrm{~ms}$ after the initiation, 
and it was exponentially dropped immediately. The magnitude of the pick-pressure was also considerably dropped along with the distance as the peak pressure reached 325,330 , and $268 \mathrm{MPa}$ at 204,408 , and $612 \mathrm{~mm}$ respectively from the blasthole bottom. The water deck blasting (WDB) shows a smaller initial peak pressure of $168 \mathrm{MPa}$ at $1.63 \mathrm{~ms}$ (Figure 4b). Interestingly, multiple peaks were observed in WDB simulation at 2.83, 4.09, 4.60, and $9.30 \mathrm{~ms}$ where their pressures are 222, 144,150 , and $210 \mathrm{MPa}$ respectively. Approximately $200 \mathrm{MPa}$ of a thick shock wave was observed after $5.48 \mathrm{~ms}$, which continues about $4 \mathrm{~ms}$ and gradually reduced. Somewhat similar rock mass damage trends were observed from the AUTODYN/ANSIS simulations of NB and WDB which were depicted in Figure 5a-1 to 5a-4 and Figure $5 b-1$ to $5 b-4$ respectively.

(a) Normal blasting (NB)

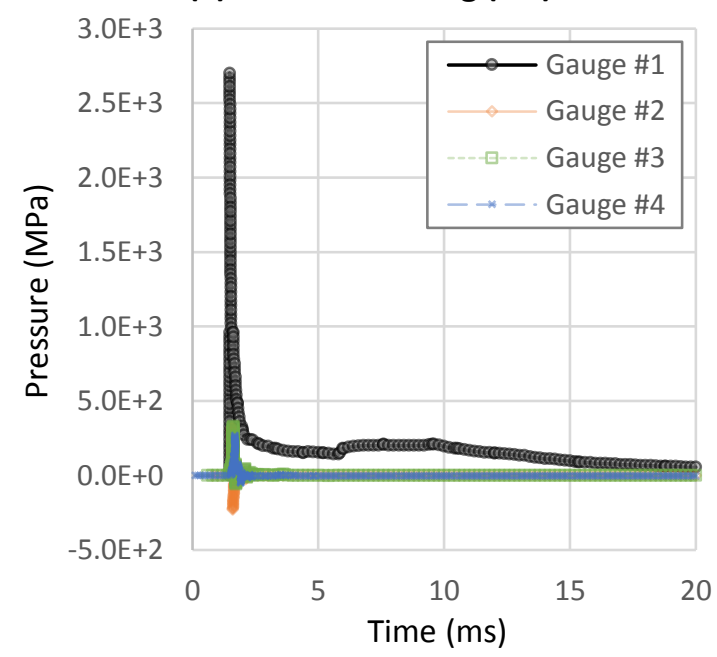

(b) Water deck blasting (WDB)

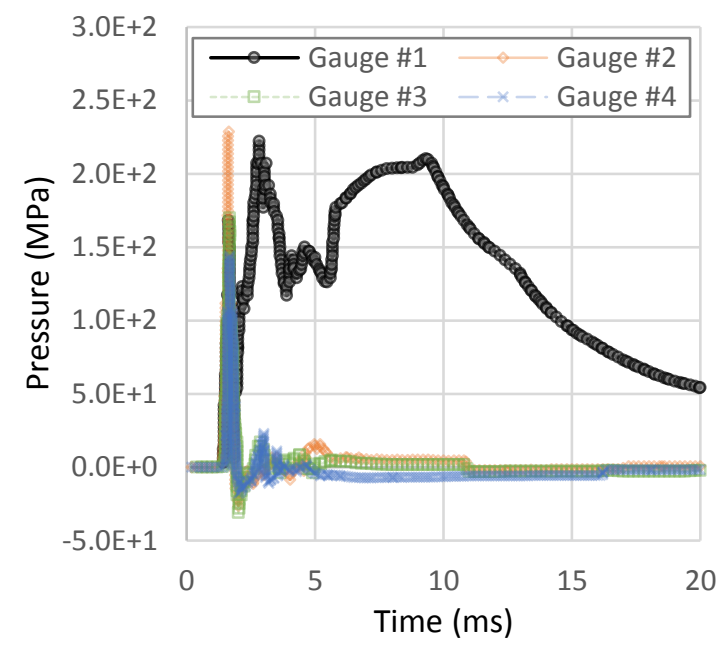

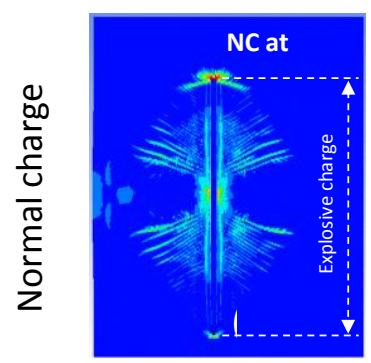
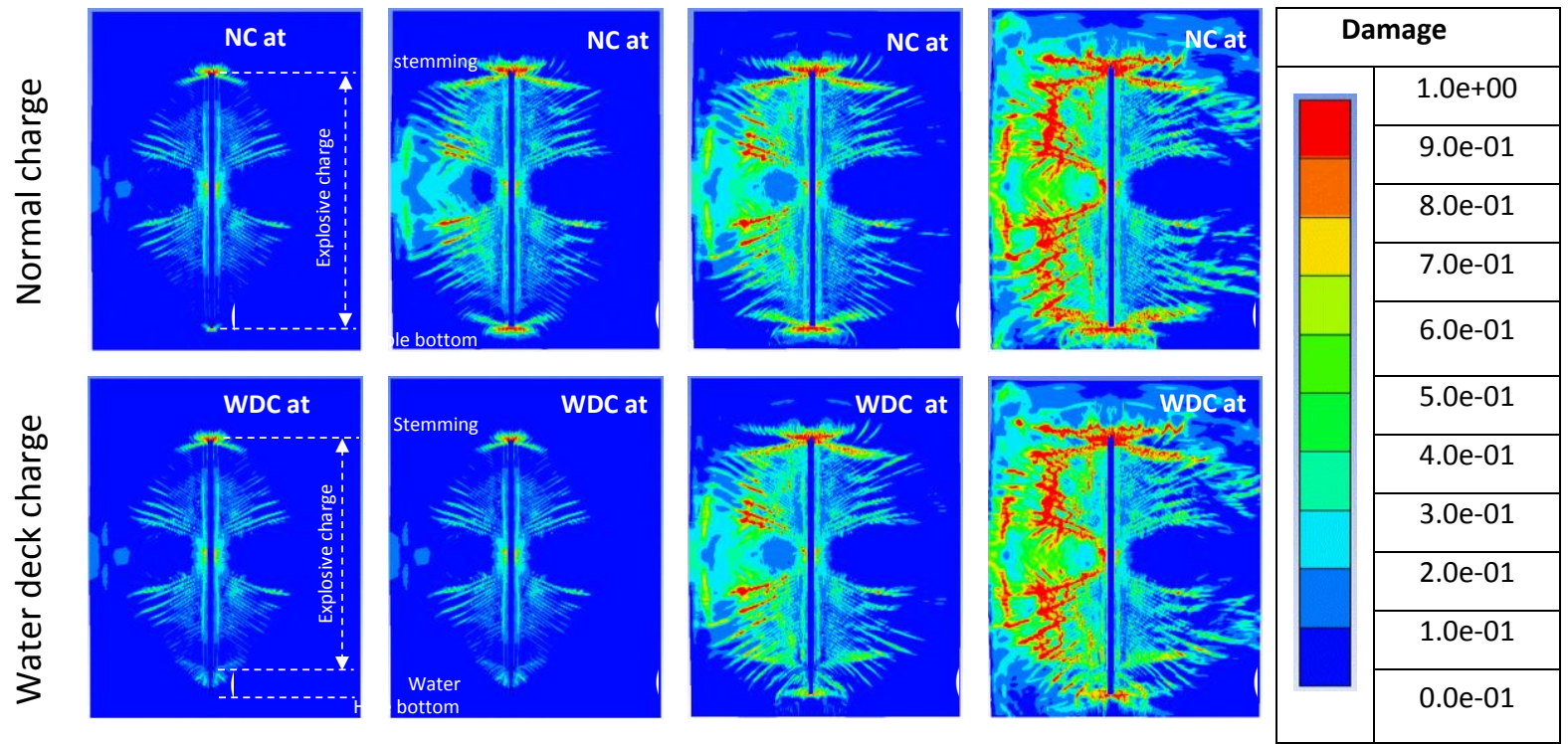

Figure 4. Time and pressure tendencies at the borehole bottom of normal blasting (a) and water deck blasting (b) from AUTODYN simulations with their graphics representing the level of damages at 1.6, 2.0, 2.2, and 3.0 ms respectively. 


\section{$4 \quad$ Field experiment}

A trial of water deck blasting (WDB) using a high hydrophobic powder (HP) was conducted on a basalt quarry in Queensland, Australia. The HP is a blended powder product which is used as a multipurpose barrier to seal off problematic water in blast holes. In the trial, the HP isolates toe water and creates a completely dry hole for the immediate loading of explosives, which turns wet holes into dry holes instantly as there is no curing time needed.

\subsection{Blasting design}

The density of the columnar basalt was $2.8 \mathrm{~kg} / \mathrm{m}^{3}$, which shows medium to high strength having a Rock Quality Designation (RQD) of 60 to 80 with regular joints. 139 blastholes with a diameter of $102 \mathrm{~mm}$ and the average depth of $14.5 \mathrm{~m}$ were drilled as the staggered pattern, with burden and spacing of 3.5 to $4.0 \mathrm{~m}$ respectively. Among the blast holes, 23 holes in one area present water. The water depths varying from $0.1 \mathrm{~m}$ to $5.9 \mathrm{~m}$ and the water level was maintained below $3 \mathrm{~m}$ before explosive loading. The quarry had been used ANFO but started to use Emulsion Explosive to prevent adverse effects water contaminated ANFO. For the trial, instead of loading the costly Emulsion Explosive, one litre of high hydrophobic powder (HP) was poured into the 23 watery blast holes before loading ANFO. The granular powder type of HP creates a structural water seal on top of the water, which completely decouples ANFO from the water at the bottom. The stemming height was maintained from 2.5 to $2.8 \mathrm{~m}$ in each hole and around $30 \%$ of explosives were reduced for those watery 23 holes. The charge pattern of the watery blast hole and photos of before and after blast are demonstrated in Figure 5.

\subsection{Field observations of the water deck blasting (WDB) effects}

The blast was examined by visual inspections of muckpile shape, fragmentation, and toe cut performance. As shown in Figure 5-c, there was no evidence of toxic fumes caused by contaminated ANFO which can be an evidence of complete separation of water and the ANFO in the blastholes. Engineers in the mine were satisfied with results of the trial blast. As shown in Figure 5-d, muckpile was properly thrown and fragmented without having excessive oversize rocks. The mine often experienced bad toe cut performances, especially at the watery area. However, the trial water deck blasting results a flat floor overall area including the location of the 23 watery hole as shown in Figure 5-e. In summary, the HP perfectly sealed the water at the bottom of those 23 watery holes, which facilitates the ideal detonation of the loaded ANFO column. In succession, the maximised explosion energy intensifies rock breaking performances with possibly reacting with the water column at the bottom of the blast hole. 

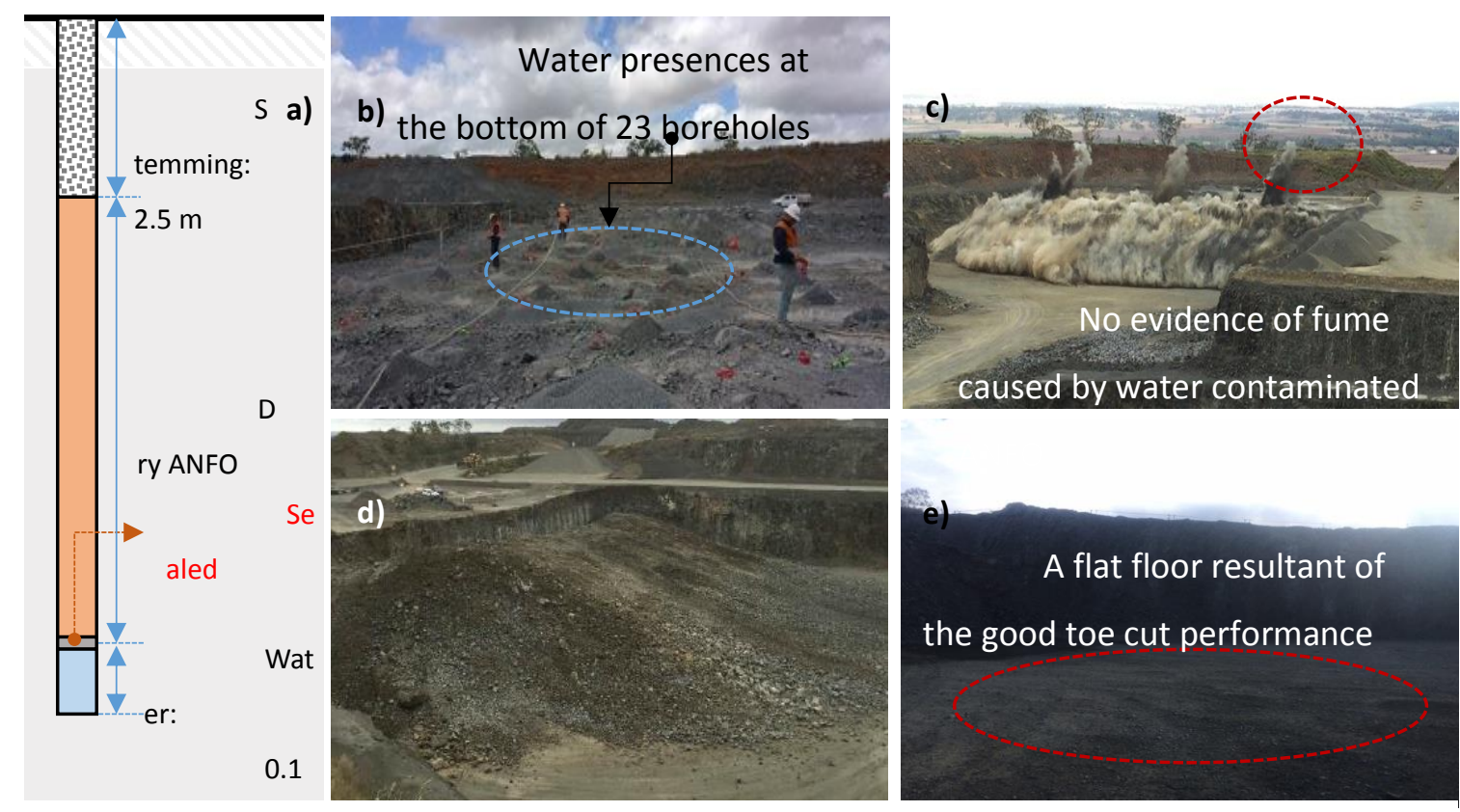

Figure 5. Water deck blasting (WDB) trial at a basalt quarry. (a) Charge pattern, (b) charging process, (c) blasting, (d) after blast and (e) after mucking out

\section{Discussions}

In the numerical analysis in Chapter 3, although the magnitude of the shock wave from the water deck blasting (WDB) on the blasthole bottom was decreased, a similar degree of damages was observed with the normal blasting (NB). Interestingly, few exotic phenomena were observed from the water deck blasting (WDB). The shock wave from WDB becomes thicker and demonstrates multiple peak oscillations. In addition, reflected waves at the boundaries of explosive-water and water-rock generate more complex shock wave interactions at the lower section of the blasthole. These unique phenomena could be related to the clean toe-cut results in the field WDB experiment.

As far as authors' knowledge, chemical and physical mechanisms of a water deck (relatively small amount of water than the amount of explosive) behaviour under the sudden dynamic blast load have not been studied yet. Considering the results from the field work and the numerical simulation, a logical deduction can be made to explain the effects of WDB referring the extreme water' and 'the steam explosion'.

Unlikely water in an ambient condition, water exhibits unique behaviours beyond it's critical point $\left(374.14^{\circ} \mathrm{C}, 22.09 \mathrm{MPa}\right)$ by undergoing dramatic changes, in both structure and bonding characteristics where the distinction of gas and liquid has disappeared ${ }^{31}$. Under the extreme condition, water (the extreme water or supercritical water) more act as a solvent and a catalyst ${ }^{32}$. These exotic behaviour have been widely used in industries, e.g., nuclear engineering, supercritical 
water gasification, and biomass productions. A recent study by Wu et al. ${ }^{33}$ discovered the catalytic behaviour of water under extreme conditions by promoting oxygen transport in the ChapmanJouguet (CJ) state during the pentaerythritol tetranitrate (PETN) explosion. It has been found that water is not just an end product of explosion but has a role in catalysing complex explosive reactions. The study is not a case of an external water behaviour during the explosion process, but it shows different roles of water under the extreme condition that can imply positive actions of water deck to increasing rock breakage performances.

The water deck (isolated water) must have undergone a rapid phase transformation due to the high energy induced by the detonation of the explosive column on top. To explain the advantageous effects of water deck at the bottom of explosive column, the mechanism of rapid heat transformation should be investigated as it results in violent water vaporisation. If the bottom water deck triggers a steam explosion phenomenon, the effect of the gas (vapour) energy would be significant as 1 litre of water creates about $1700 \mathrm{~m}^{3}$ of vapour. The steam explosion causes by rapid vaporisation of water which is considered as a critical hazard in many industries. In the nuclear engineering, the energetic steam explosion at the nuclear reactor has long been considered as a purely physical heat transform of hot molten metal to water but the role of exothermal chemical oxidation has been discussed ${ }^{34}$. The steam explosion due to physical heat transfer requires extremely fast heat transfer rate. In the nuclear engineering, this rapid heat transfer is explained with an assumption of sudden molten metal dispersion to micro sizes ${ }^{35}$. If the steam explosion occurs in the WDB, the mechanism of a rapid heat transfer from the explosive explosion to water deck at the hole bottom must be discovered. The mechanism of steam explosion is still obscure, and more information on the steam explosion on nuclear engineering can be found from the listed references: ${ }^{36-39}$.

In case of water deck blasting (WDB), the precursor shock wave, which compresses the rock is delivered from the shock front of the explosion reaction zone. The shock wave would be thicker, and its magnitude would be decreased when it is passing through the water column at the blasthole bottom due to the high impedance difference. Then, the steam explosion would be followed which generates excessive pressures. The evidence of water deck steam explosion has not been captured in the AUTODYN simulation in this study as it requires a multi-fluid and dimensional model with assumptions for many uncertainties of the phenomenon.

\section{Conclusion}

In general surface mine blasting principles, the water in a borehole customarily pumped out before loading ANFO or replacing with emulsion-type explosives which have high water resistance. 
The presence of water in the borehole is one of the critical agendas for mining companies not only as it decreases the productivity of the mine but also increases the safety issues.

The study introduces a new concept of blasting method, water deck blasting (WDB), prevents adverse effects of water at the borehole bottom as well as maximises the beneficial effects of water on rock breaking mechanism. The core of the water deck blasting (WDB) is the complete isolation of water from the explosive column in a borehole. The separation of water at the borehole bottom facilitates the complete detonation of ANFO under the dry condition. In addition, the interaction of the maximised explosion energy and the water generates continuous pressure transformation at the borehole bottom and extends the action moments of blast incident energy into the rock masses. These phenomena have been observed from the numerical simulations by AUTODYN. A hypothesis on the steam explosion of exerting extreme explosive detonation energy into isolated water has been proposed to understand the unique phenomena of the water deck blasting (WDC). As a future work, more sophisticated researches on the water deck steam explosion are required to prove the hypothesis.

A field experiment has been carried out at a basalt mine in Queensland, Australia to examine the effects of WDB. Among 139 blastholes, 23 holes were defined to contain water at the bottom, which ranges from $0.1 \mathrm{~m}$ to $3.0 \mathrm{~m}$. A high hydrophobic powder was applied to create a structural layer to seal the water. As results, the blasting produces a satisfactory fragment distribution without boulders. Especially, it derived a flat floor, which implies the effectual influence of WDB. Although the exact effects of the isolated water at the blasthole bottom have not been clarified in this study due to the complex undisclosed mechanisms, the advantageous actions of the isolation of water at blasthole have been verified through the numeral analysis and the field experiment. The water deck blasting (WDB) method expects to bring positive contributions on surface mine blasting. 


\section{List of Figures}

Figure 1. Rock strength and stress wave velocity comparison of dry and wet boreholes. (a) Dry borehole, (b) Wet borehole due to the water table at the bottom of borehole, and (c) Wet borehole sealing the water at the bottom of borehole.

Figure 6. The relation between Poisson's Ratio and Blasting Damage Zone (BDZ).

Figure 7. Schematic view of the 2D numerical model for water deck blasting.

Figure 8. Time and pressure tendencies at the borehole bottom of normal blasting (a) and water deck blasting (b) from AUTODYN simulations with their graphics representing the level of damages at 1.6, 2.0, 2.2, and 3.0 ms respectively.

Figure 9. Water deck blasting (WDB) trial at a basalt quarry. (a) Charge pattern, (b) charging process, (c) blasting, (d) after blast and (e) after mucking out. 


\section{References}

1. Ni O, Zhang K, Yu Z, Tang S. Powdery emulsion explosive: a new excellent industrial explosive. Journal of Energetic Materials. 2012;30(3): 183-195.

2. Wang Z-I, Li Y-c. Numerical simulation on effects of radial water-decoupling coefficient in engineering blast. ROCK AND SOIL MECHANICS-WUHAN-. 2005;26(12): 1926.

3. LUO Y-g, LUO Q, ZONG Q. Study on Mechanism of Rock Blasting Fragmentation of Water Coupling Charge in Bore Hole. Journal of Anhui University of Science and Technology (Natural Science). 2004: S1.

4. Wenchen SZLQJ. Research of the Bottom Water Cusion Blasting of Blasthole and Its Application [J]. METAL MINE. 2000;7: 004.

5. Cui Z-D, Yuan L, Yan C-L. Water-silt composite blasting for tunneling. International Journal of Rock Mechanics and Mining Sciences. 2010;47(6): 1034-1037.

6. Huang B, Li P. Experimental investigation on the basic law of the fracture spatial morphology for water pressure blasting in a drillhole under true triaxial stress. Rock Mechanics and Rock Engineering. 2015;48(4): 1699-1709.

7. Kim E, Changani H. Effect of water saturation and loading rate on the mechanical properties of Red and Buff Sandstones. International Journal of Rock Mechanics and Mining Sciences. 2016(88): 23-28.

8. Cole RH, Weller R. Underwater explosions. Physics Today. 1948;1: 35.

9. Ray S, Sarkar M, Singh T. Effect of cyclic loading and strain rate on the mechanical behaviour of sandstone. International Journal of Rock Mechanics and Mining Sciences. 1999;36(4): 543549.

10. Eberhardt E, Stead D, Stimpson B. Quantifying progressive pre-peak brittle fracture damage in rock during uniaxial compression. International Journal of Rock Mechanics and Mining Sciences. 1999;36(3): 361-380.

11. Fuenkajorn K, Phueakphum D. Effects of cyclic loading on mechanical properties of Maha Sarakham salt. Engineering Geology. 2010;112(1): 43-52.

12. Zhou Z-L, Zhang G-Q, Dong H-R, Liu Z-B, Nie Y-X. Creating a network of hydraulic fractures by cyclic pumping. International Journal of Rock Mechanics and Mining Sciences. 2017;97: 5263.

13. ANSYS $^{\circledR}$. AutoDyn. Release 17.0 ed.; 2017.

14. Ouchterlony F, Nyberg U, Olsson M, Bergqvist I, Granlund L, Grind H. The energy balance of production blasts at Nordkalk?s Klinthagen quarry. Explosives and Blasting Technique. Taylor \& Francis; 2003:193-203.

15. Sanchidrian JA, Segarra P, López LM. Energy components in rock blasting. International Journal of Rock Mechanics and Mining Sciences. 2007;44(1): 130-147.

16. Needham CE. Height of Burst Effects. Blast Waves. Berlin, Heidelberg: Springer Berlin Heidelberg; 2010:201-246.

17. Zheming Zhua $\tilde{A}$, Xiea $\mathrm{H}$, Mohantyb B. Numerical investigation of blasting-induced damage in cylindrical rocks. International Journal of Rock Mechanics \& Mining Sciences. 2008;45: 111121. 
18. Kim J-G, Song J-J. Abrasive water jet cutting methods for reducing blast-induced ground vibration in tunnel excavation. International Journal of Rock Mechanics and Mining Sciences. 2015;75: 147-158.

19. Park D, Jeon S. Reduction of blast-induced vibration in the direction of tunneling using an airdeck at the bottom of a blasthole. International Journal of Rock Mechanics and Mining Sciences. 2010;47(5): 752-761.

20. Mitelman A, Elmo D. Modelling of blast-induced damage in tunnels using a hybrid finitediscrete numerical approach. Journal of Rock Mechanics and Geotechnical Engineering. 2014;6(6): 565-573.

21. Koneshwaran S, Thambiratnam DP, Gallage C. Blast response of segmented bored tunnel using coupled SPH-FE method. Structures. 2. Elsevier; 2015:58-71.

22. Persson PA, Holmberg R, Lee J. Rock blasting and explosives engineering: CRC PressI LIc; 1994.

23. ANSYS. AUTODYN. R18.2 ed.; 2018:Academic.

24. Rogers GFC, Mayhew YR. Thermodynamic and transport properties of fluids: Blackwell Oxford; 1981.

25. Laine L, Sandvik A. Derivation of mechanical properties for sand. Proceedings of the 4th AsiaPacific Conference on Shock and impact loads on structures, CI-Premier PTE LTD, Singapore. 361. ANSYS Inc.; 2001:368.

26. McQueen R. Selected Hugoniots. Los Alamos Scientific Lab TRLA-4167-MS, Albuquerque, New Mexico. 1969.

27. Herrmann W. Constitutive equation for the dynamic compaction of ductile porous materials. Journal of applied physics. 1969;40(6): 2490-2499.

28. Riedel W. â Beton Unter Dynamischen Lasten: Meso-Und Makromechanische Modelle Und Ihre Parameter, Fraunhoferâ Ernst-Mach-Institut, Freiburg/Br. ISBN 3-8167-6340-5; 2004.

29. Collins $\mathrm{G}$, Melosh $\mathrm{H}$, Wünnemann $\mathrm{K}$. Improvements to the $\varepsilon$ - $\alpha$ porous compaction model for simulating impacts into high-porosity solar system objects. Int J Impact Eng. 2011;38(6): 434439.

30. Riedel W. 10 years RHT: a review of concrete modelling and hydrocode applications. Predictive modeling of dynamic processes. Springer; 2009:143-165.

31. Ohtaki H. Effects of temperature and pressure on hydrogen bonds in water and in formamide. Journal of Molecular Liquids. 2003;103: 3-13.

32. Smith I. Single-molecule catalysis. Science. 2007;315(5811): 470-471.

33. Wu CJ, Fried LE, Yang LH, Goldman N, Bastea S. Catalytic behaviour of dense hot water. Nature chemistry. 2009;1(1): 57.

34. Epstein $\mathrm{M}$, Fauske $\mathrm{H}$, Theofanous $\mathrm{T}$. On the mechanism of aluminum ignition in steam explosions. Nuclear Engineering and Design. 2000;201(1): 71-82.

35. Kim B-J. Heat transfer and fluid flow aspects of a small scale single droplet fuel-coolant interaction. Wisconsin Univ., Madison (USA); 1985.

36. Theofanous T. The study of steam explosions in nuclear systems. Nuclear Engineering and Design. 1995;155(1-2): 1-26.

37. Fletcher DF. Steam explosion triggering: a review of theoretical and experimental investigations. Nuclear Engineering and Design. 1995;155(1): 27-36. 
38. Ciccarelli G, Frost DL. Fragmentation mechanisms based on single drop steam explosion experiments using flash X-ray radiography. Nuclear Engineering and Design. 1994;146(1): 109-132.

39. Dombrovsky LA. Steam explosion in nuclear reactors: Droplets of molten steel vs core melt droplets. International Journal of Heat and Mass Transfer. 2017;107(Supplement C): 432438. 